\title{
Global Engineering Leadership - Design and Implementation of Local and International Service Learning Curriculum for Senior Engineering Students
}

\author{
Elizabeth A. Croft, Ph.D., P.Eng. ${ }^{*}$, FEC, Paul Winkelman, Ph.D.., Alaya Boisvert, M.Sc. ${ }^{* \dagger}$, Kristin Patten, B.A. ${ }^{\dagger}$ \\ ${ }^{*}$ Faculty of Applied Science and ${ }^{\dagger}$ Community Learning Initiative, University of British Columbia \\ elizabeth.croft@ubc.ca
}

\begin{abstract}
Engineering students are typically wellprepared with technical knowledge and skills that are prerequisite to solving problems. However, recent changes to the Canadian Engineering Accreditation Board recognize that contributions made by engineers to our society also depend upon proficiency in key nontechnical areas, including teamwork and leadership capacity, service, and global awareness.

In this paper, we argue that service-learning pedagogy addresses many desired graduate attributes required for accreditation. We then discuss the design and implementation of a new service-learning elective course series aimed at providing students with leadership education and service experiences that address these attributes in both local and global contexts. Finally, we reflect on the short term, qualitative outcomes of the course series that has run in pilot form for the past two years with approximately 20 students per year, and has recently been approved as an ongoing part of the $U B C$ engineering curriculum.
\end{abstract}

Keywords: Graduate attributes, community service learning, international service learning, servant leadership.

\section{INTRODUCTION}

The University of British Columbia (UBC) Global Engineering Leadership course series answers three calls - from society, from our profession, and from our students - to develop the leadership capacity in graduating engineers to address the many challenges facing humanity. The societal call comes from the recognition that societal problems are interconnected with environmental and technical problems, demanding consensus-building through partnerships and service. The professional call comes from the bodies like the Canadian Engineering Accreditation Board (CEAB) who echo these same sentiments through their list of graduate attributes required of all graduating engineers [1]. Finally, the student call is demonstrated by the passion students have shown for service and leadership development through their activities with organizations like Engineers Without Borders (EWB). Indeed, the local EWB chapter at UBC has supported the design and implementation of the curriculum for this course

\subsection{Curriculum Needs and Challenges}

The Canadian Engineering Accreditation Board $(\mathrm{CEAB})$ is responsible for ensuring the quality of engineering programs across Canada. Program accreditation is granted based on compliance a set of criteria, including the attributes of those graduating from the program [1]. Graduate attributes, while challenging to assess, emphasize the outcome of the program and the potential of the graduate to contribute to society.

The list of graduate attributes presented by the CEAB is extensive and a great number, (disproportionate to the corresponding number of academic units) relate to content not traditionally taught in technical engineering courses, including: being a member and a leader of a team; communications skills; professionalism; impact of engineering on society and the environment; ethics and equity; economics and project management; and life-long learning. As a result, engineering educators are looking to new pedagogical models to address the development and demonstration of these attributes in students. In particular, local, community service learning (CSL) and international service learning (ISL) (collectively SLService Learning) are increasingly relevant since many of the CEAB attributes are implicitly, if not explicitly, cultivated through student involvement in communitybased projects, especially when linked to curricular requirements [2].

\subsection{Addressing Graduate Attributes: Service Learning and Leadership Experience}

The fundamental pedagogical framework for SL is rooted in the idea that experiential education broadens student's world-view by building from their existing mental models. When faced with a concrete experience and given the opportunity to reflect thoughtfully on what has transpired, students can become active participants in 
their learning. Drawing on conclusions about what their experience means, students can analyze and synthesize the personal, academic and professional implications of the experience. Then, applying these new conclusions to a future experience, students can test the validity of their notions [3]. Thus, a vital component of SL is the practice of critical reflection [4].

SL also fits well within the benchmark of "Active and Collaborative Learning" identified within the National Survey of Student Engagement (NSSE). This area encompasses student engagement activities such as: asking questions, class presentations, teamwork in class, discussions and learning activities outside of class, and involvement in community based projects. SL is one of ten identified "high impact activities"- activities that have been shown to increase the level of student engagement and correlate highly with NSSE gains on student learning outcomes [5].

The implementation of SL activities, particularly in engineering design courses, is becoming well accepted in the academic teaching and learning community. The Engineering Projects in Community Service Learning (EPICS) [6] project was initiated at Purdue University in the nineties, and has been expanded to at least 15 other universities. At the University of Toronto, CSL activities were successfully introduced into first year engineering design curriculum in 2003 [7]. SL has been shown to address the graduate attributes listed above, and compares favorably with the recommendations set by the Boyer Commission [8]. Reciprocally, through SL projects, community partners can achieve their own goals and addressed critical issues identified as community priorities [9].

Broadly, SL fosters meta-skills such as creative problem-solving and critical thinking and offers students an opportunity to develop practical skills required of engineering graduates who will become good communicators, conscientious professionals, servant leaders, and engaged global citizens. This is particularly important for engineering education, which has a longstanding reputation of being predominantly technically focused while limited in other developmental areas essential to the profession [2].

Many of the outcomes of SL pedagogy align with desirable leadership qualities. Leadership development has been explored extensively in engineering and in a wide range of other disciplines. The traditional engineering perspective casts leaders as having the ability to recognize problems, establish goals and to make decisions [10]. In the context of higher education, [11] speak of "transformative" leadership where a leader is a "change agent" (p. 8). The "change" they speak of is social change; leadership is therefore a group process and is inherently value-laden. Spears champions the concept of servant-leadership, countering traditional, hierarchical views of leadership that considers people to be resources rather than collaborators [12]. Servant-leadership values persuasion over authority and control, rejection of behaviour over rejection of the person, and stewardship over ownership. To help ground these concepts and bring them to life for students, classroom teaching must be supplemented with extra-classroom activities. To this end, service-learning activities provide an ideal context in which these concepts can be explored.

\section{COURSE SERIES DESIGN}

Designed as a CSL/ISL two-course series, Global Engineering Leadership, introduces engineering students from a broad range of backgrounds to concepts, theory and practice of engineering leadership. Topics include engineering leadership characteristics and the nature of servant-leadership; individual and cultural differences and management contexts; managing change, conflicts, and crises; real-world ethics and core values. The aim of this course is to allow students to explore the space before the technical engineering design process starts - and consider the intersection between community value systems and needs, the practice of engineering, and the role of engineers in serving communities. In particular the course speaks to the fact that public needs and user expectations are often vague and ill-defined. This course operates in this transition area between unmet societal needs and developing engineering project requirements. By providing a SL context, students are given an opportunity to explore these issues in an immersive experience that cannot be replicated in the engineering classroom.

The series was developed through a partnership between UBC Applied Science, the UBC Community Learning Initiative, UBC's International Service Learning Initiative, UBC Mechanical Engineering and the NSERC Chair for Women in Science and Engineering, BC/Yukon. EWB students provided input and content for the curriculum. Our international partner, local faculty and a wide range of community members, including a Senator, an MLA and the CEO of a public regulator all provided lectures and content for the course. A broad range of partnerships, along with department and faculty support to establish these relationships, were essential to address the challenging goals of this course.

The course series spans two summer sessions, with the first course, APSC 461, offered over six weeks in May/June. A portion of the 461 students apply to participate in the second course, APSC 462, offered in July/August as a ISL placement in Mexico.

\section{GLOBAL ENGINEERING LEADERSHIP (CSL)}

In APSC 461, students read and respond to articles, attend lectures and workshops presented by guest speakers, follow up with reflections and instructor-led classroom discussions, and complete a CSL project. 


\subsection{Readings}

Prior to attending the presentations of the guest speakers, students are required to review and respond to readings provided by the speaker (and, occasionally, the instructor). A typical reading comprises one long or two short articles. The responses, one per article, are relatively short and contain four sections: i) argument requires student to demonstrate an understanding of the central tenet of the article; ii) context reminds students that arguments are subject to time and place and encourages students to connect the argument to a particular person or group rather than a nameless voice; iii) critique is designed to bring out the students' own voice and personalize the reading; iv) connection forces students to locate the particular topic of the article in terms of the previous topics and overall course objectives.

\subsection{Guest Speakers}

Guest speakers include practicing engineers, sociologists, sustainability researchers, politicians and international development workers. Presentations take the form of lectures, workshops and panel discussions. The speakers and topics are selected to address the course objectives: sustainability, leadership, diverse community values, environmental policy, community participation, activism, poverty and creativity. Although the use of diverse guest speakers affects the continuity of the course, this concern is outweighed by the knowledge, current relevance, and the passion that the speakers bring to the class. Question and answer sessions provide students with the opportunity to further probe issues of personal interest.

\subsection{Reflection Exercises}

Ash and Clayton [13] speak of the "centrality of reflection in service-learning" (p. 139). Reflections encourage students to explore their learning and understanding, implicit or explicit, in light of their service-learning experience and assign meaning to that experience with a view to future outcomes. To encourage students to engage in a meaningful and critical thought process, Ash and Clayton suggest a framework following the three phases of description, analysis and articulation. Description explores experience through analyses that may be academic (course concepts, theory and practice), personal (feelings, assumptions, etc.) or civic (the common good). Articulation expresses the learning outcomes and answers the four questions of "articulate learning": what did I learn? how did I learn it? why is it significant? and how will I use this learning in the future?

In addition to being part of the SL process, reflections form an important follow-up to the main lectures/workshops given by guest speakers. Immediately following the guest speaker presentation, students spend 20 minutes writing a reflection. This activity helps students to focus on the lecture and to contemplate connections between the presentation and previous material covered in the course in a personalized form. Once submitted, course instructors utilize these reflections to assess student understanding. Should the reflections point to incomplete understandings or significant issues that merit further discussion, time can be set aside in later sessions to address these concerns

\subsection{Classroom Discussions}

Classroom discussions follow the presentations and serve multiple purposes. First, they provide a forum for further discussion of topics raised by the guest speaker's presentation, usually without the speaker being present. Second, they allow for reviewing some important points raised in the readings that may have been missed by the students and not covered by the guest speaker. Third, the time gives space for taking care of "business" items, such as presenting projects and discussing subsequent issues and introducing or reviewing assignments.

\subsection{Projects and Community Partnerships}

The concepts developed through the readings and guest lectures are supplemented by CSL projects. These projects are intended to immerse students in a community setting. The ideal project is relatively narrow in scope, but retains sufficient ambiguity such that students are forced to struggle with needs assessment and problem formulation.

The key project deliverables are a report and presentation to the community group that translates community needs and values into technical information aimed to assist the community with their objectives. In contrast to capstone projects, the technical design portion in this course project is limited. This choice allows students to concentrate their efforts on providing a meaningful, organized service package to the community rather than focusing on design and analysis - an objective much better handled in more focused capstone design.

It is essential that the problem addressed is community-based, requiring students to come face-to-face with members of the target community. The contact generally comprises initial meetings to ask questions and collect the necessary information and a second contact session where students present their findings and recommendations.

One of the essential components of an effective and mutually beneficial CSL project is the appropriate matching of the skills required to complete the project (i.e., community goal or need) and proficiency available (i.e., student capacity). If this requirement is overlooked, neither students nor community partners receive the optimal benefits of the partnership. The expertise of the UBC Community Learning Initiative was essential to find projects of appropriate scope. 


\section{$4 \quad$ Global Engineering Leadership (ISL)}

During APSC 462, students are placed with Tsomanotik, a community organization based in Chiapas State, Mexico [14]. Tsomanotik is a demonstration centre for just and sustainable community development. Their vision is for solidarity and a more just society where marginalized groups in Chiapas are heard and play an active role in the community development process. Tsomanotik's demonstration centre showcases ecoagricultural techniques as well as a variety of alternative energy and appropriate technology prototypes.

UBC Students have assisted Tsomanotik in improving the function of alternative energy and appropriate technology prototypes on-site, as well as building foundations to implement successful prototypes in community settings. All students work in multidisciplinary teams of Mexican and Canadian university students, under the guidance of Tsomanotik staff.

\subsection{Student Assignments}

Course assignments in APSC 462 strive to foster a series of learn-act-reflect cycles that begin early in the practicum. These cycles continue throughout the practicum and into the first two weeks after return to the university and re-engagement with their "home community", allowing students to further reflect on their experience, refine their thinking, and polish their work.

The students prepare and submit the following documents:

Reflective Essays: Students write three reflective essays during their placement based on three different topics discussed in APSC 461 and related to the work that they are doing on their placement.

Daily Journal/Log Book: Students are required to record their reflections on their daily experiences as well as document their work on the appropriate technology prototypes developed at Tsomanotik

360 degree review: This assignment is derived from the professional 360 degree review process: i.e, obtaining critical feedback from reports, peers and managers that is aggregated and compared to a person's self review in mediated, reflective sessions [15]. Students are given a template, and asked to assess their development during their placement related to teamwork, leadership, service, valuing others, communication and other key attributes. Assessments of each student are gathered from $3-5$ people that have been significant in the student's placement (project leaders, peers, program staff). ISL staff facilitate the feedback process during a visit to the international site. At the completion of the process, the student is asked to write a reflective essay on the process of doing the 360 degree review, linking back to the placement and the course content.

\section{COURSE PROGRESS}

Overall, participation in the course is steadily growing; In the CSL course, 16 students participated in the first year,
21 in the second year and 29 are currently registered. The ISL placements have been considerably smaller, 3 in the first year, 4 in the second and 5 in the third year. The course series has also moved from a pilot stage through review by the faculty curriculum committee and finally approved by the UBC senate as a technical elective (APSC 461) and a technology in society elective (APSC 462).

Post course, students exhibit a strong interest in participating in leadership and community service activities. Some of the students continue to be involved in community and international service activities after the course completion. Three students (two from the ISL placement, one from the 2012 APSC 461 course) are members of the EWB Global Engineering team on campus. Two students from the 2011 APSC 462 ISL placement have continued to be involved in the ISL program as student leaders - participating in selection of students, facilitating and shaping of pre-departure workshops, and sharing their experiences and learning with new students about to participate in APSC 462.

\subsection{CSL Project Experience}

Overall, the CSL projects have been relatively successful. However, finding projects that substantially meet CSL requirements and which can be completed within the short six-week course time frame can be quite challenging. For this reason, it is important to keep an active community network from which projects can be solicited. Often, community problem statements are vague, vast or highly technical, or do not offer meaningful community contact. In all cases, however, the students made the projects "work" and brought them to a successful conclusion. This demonstrates that the students were all able to make some sense of the project and in the process develop some leadership qualities, such as empathy, awareness, and community building. The act of presenting to the community fosters a sense of professionalism, helping them move from a student role to that of knowledgeable consultant.

In some cases, students come with their own, preexisting projects. Although it may seem beneficial to have a ready-made project that can be further developed, students can find themselves committed to traditional design-build project and fail to consider the connection between community value systems and needs and engineering design. For this reason, it is important that the student project proposal be written and reviewed early in the course to ensure that the students achieve the course learning objectives.

Furthermore, despite the short time span, prior engagement is not essential. In a project new to UBC, students worked with a citizens group to develop more awareness and community participation around a local proposed engineering project. Within the course timeline, students involved demonstrated a high level of engagement with the community group and successfully 
presented a balanced and informative presentation to a community group of around forty people.

While many students show significant development through the CSL process, some students can miss the opportunity provided by the challenges presented in this course because the problems they have previous encountered have been well scoped, limited and presented in a purely engineering context. Some student feedback has indicated frustration arising from the ill-defined nature of the initial community project problem statements, rather than a recognition that translating an illdefined need to a more well defined state was one of learning objectives for the course. On the other hand, this feedback also points to the critical role that staff from the Community Learning Initiative have in helping community organizations to define and scope projects prior to student involvement. Successful project definition often requires multiple conversations between university staff and community organizations, and is a learning process that is ideally facilitated in long-term relationships so that lessons from one year can be carried forward to the next.

Another challenge is to help students move beyond the "student" role in taking on a service project. Students often mention that they are students within their report and sometimes develop a tentative or apologetic tone in their writing. As noted above, students are encouraged to think through the project as if they were actual engineering consultants. Rather than trying to second guess what the instructors want to hear, students are encouraged to write the report that best captures their understanding of the community narrative and needs and to be open to a wide number of technical and nontechnical solutions that could be used assist the community achieve its goals.

\subsection{ISL Project Experience}

Over the past two years, teams of UBC and Mexican students have focused primarily on Alternative Energy projects, in order to develop low-cost appropriate technologies that utilize no electricity. The Tsomanotik site became a facility for these technologies to be designed, built and tested. The long-term goal is for similar technologies to be implemented into surrounding communities to reduce energy costs for local citizens

In 2011 the primary project was to develop, troubleshoot and implement a solar hot water heating system for the showers of a new bathroom. The challenge was to build a device that was low-cost (in local terms), built using local materials, as well as easy to replicate and maintain by local people with limited technical skills. The team outlined the project scope and key challenges (lack of flow to the system due to insufficient water pressure from the municipal water system); brainstormed 10 potential solutions; and finally designed, created and tested three prototypes (a hand-pump, bike-powered pump and rope and pulley-system). As a result, sufficient pressure was achieved and the solar hot water system provided hot water at a pressure suitable for showers. The students also provided future recommendations.

In their reflective writing one UBC team member noted that the range of the learning experience went well beyond the technical task of building a solar water heater. They recognized the value of the diversity of team member cultures and perspectives, and the challenges related to the ambiguous nature of developing appropriate technology in a "real world" setting where problems were not clearly defined and resources minimal

\section{$6 \quad$ Summary and Future development}

The near term plan for APSC 461 and 462 is to offer these courses yearly in summer session as a technical elective and impact-of-technology-on-society series for 30-35 students. The course also serves as an incubator and model for developing CSL pedagogy for other engineering courses. In the longer term, it is hoped that components of the course can be translated into core engineering design courses such that all engineering students will have a service learning experience as part of the educational path.

To improve an understanding the course benefits, the UBC ISL program is currently in the second year of a project specifically focused on evaluating learning outcomes for students participating in ISL programs. Students enrolled in both Global Engineering Leadership courses (APSC 461 and 462) will be assessed in four key areas: change agency, awareness of self in relation to others, global issues and educational impact. One of the long-term intentions of the project is to provide faculty with better tools to evaluate learning outcomes of students participating in SL programs.

\section{[1] M. J. Reeves et al., "Canadian Engineering} Accreditation Board Accreditation Criteria and Procedures," 2012.

[2] E. Tsang, Ed., Projects Than Matter, Concents and Models for Service-Learning in Engineering. 2000.

[3] D. Cone and S. Harris, "Service-Learning Practice: A Theoretical Framework," Michigan Journal of Community Service Learning, vol. 3, pp. 31-42, 1996.

[4] S. Ash, P. Clayton, and M. Atkinson, "Integrating reflection and assessment to capture and improve student learning," Michigan Journal of Community Service LearningCommunity Service Learning, no. Spring, pp. 49-60, 2005.

[5] G. Kuh, "High Impact Practices: What They Are, Who Has Access to Them, and Why They Matter." 2008. 
[6] "Engineering Projects in Community Service." [Online]. Available: http://epics.ecn.purdue.edu/.

[7] S. McCahan et al., "Engineering Strategies and Practice: Team Teaching a Service Learning Course for a Large Class," in Society for Teaching and Learning in Higher Education Conference, 2007 , p. 28.

[8] "Reinventing Undergraduate Education: A Blueprint for America's Research Universities (The Boyer Report)." Carnegie Foundation for the Advancement of Teaching, p. 46, 1998.

[9] G. Bowen, Service learning in the scholarship of teaching and learning: Effective practices. 2010.

[10] R. H. McCuen, "A course on engineering leadership," Journal of Professional Issues in Engineering Education Practice, vol. 125, no. 3, pp. 79-82, 1999.
[11] A. W. Astin and H. Astin, Leadership Reconsidered: Engaging Higher Education in Social Change. Battle Creek, MI: Kellogg Foundation, 2000.

[12] L. Spears, "Practicing servant-leadership," Leader to Leader, 2004. .

[13] S. L. Ash and P. H. Clayton, "The Articulated Learning: An Approach to Guided Reflection and Assessment," Innovative Higher Education, vol. 29, no. 2, pp. 137-154, Jan. 2004.

[14] "Tsomanotik." [Online]. Available: http://www.manotik.org/.

[15] M. Vinson, "The pros and cons of 360-degree feedback: Making it work," Training and Development, no. April, pp. 11-12, 1996. 